\title{
Maternal Zinc Supplementation Improves Spatial Memory in Rat Pups
}

\author{
Agnieszka Piechal • Kamilla Blecharz-Klin • \\ Justyna Pyrzanowska • Ewa Widy-Tyszkiewicz
}

Received: 2 November 2011 / Accepted: 3 January 2012 /Published online: 17 January 2012

(C) The Author(s) 2012. This article is published with open access at Springerlink.com

\begin{abstract}
A large body of evidence supports an opinion that adequate dietary zinc is essential for prenatal and postnatal brain development. Behavioural effects of maternal supplementation with $\mathrm{ZnSO}_{4}$ were analysed in rat pups with the Morris water task performance, a hole board and a T-maze. Wistar females during pregnancy and lactation received a drinking water solution of $\mathrm{ZnSO}_{4}$ at doses of $16 \mathrm{mg} / \mathrm{kg}$ (group Zn16) or $32 \mathrm{mg} / \mathrm{kg}$ (group Zn32). Behavioural tests were conducted on the 4-week-old male rat pups. Zinc concentration in the serum, hippocampus and prefrontal cortex of offsprings was determined by means of atomic absorption techniques. The Newman-Keuls multiple comparison test revealed an increase of climbing in the $\mathrm{Zn} 16$ group in comparison to the control group (Con) and the Zn32 group during the hole board test. ANOVA for repeated measures showed a significant memory improvement in both supplemented groups compared to the control in the probe trial on day 5 of the water maze test. $\mathrm{ZnSO}_{4}$ treatment significantly elevated zinc levels in the rat serum. Follow-up data on brain content of zinc in the hippocampus revealed significant differences between the groups and in supplemented groups correlated with crossings above the original platform position. These findings suggest that pre- and postnatal zinc supplementation may improve cognitive development in rats.
\end{abstract}

Keywords Zinc · Zinc supplementation - Spatial memory · Behavioural tests $\cdot$ Behaviour $\cdot$ Rat

A. Piechal $(\bowtie) \cdot K$. Blecharz-Klin · J. Pyrzanowska •

E. Widy-Tyszkiewicz

Department of Experimental and Clinical Pharmacology,

Medical University of Warsaw,

Krakowskie Przedmieście 26/28,

00-927 Warsaw, Poland

e-mail: piechal@hotmail.com

\section{Introduction}

Maternal zinc status influences the pregnancy and lactation outcomes. Many features of fetus and offsprings such as growth, birth weight and morbidity, mental development or behaviour depend on neonatal and early postnatal zinc availability [1-3]. Zinc is essential for the proper functioning of the immune system, bone development, sexual functions, normal taste, olfactory sensation and night vision. This transitional metal performs catalytic and structural functions as a cofactor and ensures the proper function of over 200 different enzymes [4]. In the body, it plays a role in proper hormonal status maintenance and controls the level of insulin, thymulin, nerve growth factor, thyroid hormones, testosterone and somatomedin $\mathrm{C}$.

The large amount or research is devoted to the examination of dietary zinc restriction in pregnancy and early life on risk of adulthood chronic diseases, such as obesity, type 2 of diabetes, hypertension, renal dysfunction or behavioural deficits [5, 6]. Zinc deprivation during fetal life, lactation and early postnatal period induces several neurobehavioural abnormalities, e.g. increased anxiety, memory deficits and learning impairments $[7,8]$.

Experiments in animals revealed the critical role of zinc for correct brain development and functioning of the central nervous system. The coincident expression of vesicular zinc with the development of brain structures suggests that zinc participates in neurogenesis and in the synaptic maturation $[9,10]$. Zinc is believed to play an important role in cognition and memory via its function as a neuronal messenger, modulator of synaptic transmission and cortical plasticity [11]. The influence of zinc supplementation on cognitive function may depend also on its antioxidative action.

In the central nervous system, zinc is found pooled as the protein-bound, free and vesicular form. The protein-bound pool 
includes zinc-containing enzymes or zinc-protein complexes and comprises more than $85 \%$ of the whole brain zinc. Free ionic zinc in the cytosol and intestinal fluid is quickly bound after release. Reportedly, up to $15 \%$ of vesicular zinc is located in synaptic vesicles of nerve terminals. Vesicular zinc may play a role in synaptic neurotransmission in the mammalian brain and serves as an endogenous neuromodulator of several important receptors, e.g. purinergic and opioid receptors [12].

Released zinc is a modulator of inhibitory or excitatory synaptic transmission and has been found to inhibit neuroexcitation mediated by $N$-methyl-D-aspartate (NMDA) receptors in both voltage-dependent and voltage-independent mechanisms. Chowanadisai and coworkers indicated that maternal zinc deficiency reduces expression of NMDA receptor, which is facilitated by decreased neurotropin concentration and polysialic acid-neural cell adhesion molecule in neonatal rat brain [7]. Zinc exerts a dual effect on amino-3hydroxy-5-methylisoxaol-4-propionic acid and kainate receptors. At low micromolar concentrations, it potentiates currents mediated by these receptors but induces inhibitor activity at high micromolar or millimolar concentrations [12]. In addition, zinc binds to the $\gamma$-aminobutyric acid (GABA) receptors and noncompetitively inhibits GABA-mediated responses. In many parts of the brain, zinc biphasically modulates also serotonergic and nicotinic receptors.

Zinc is unevenly distributed in the central nervous system with the highest concentrations in the olfactory bulb, the cerebral cortex and hypothalamus [13]. Another structure that contains high levels of zinc is the hippocampus, a region important for learning and memory.

The physiological significance of zinc as an endogenous neuromodulator and the role of this essential trace mineral in spatial recognition are still poorly understood and remain to be clarified. Majority of studies document the adverse effects of zinc deficiency; however, some of the research are examining zinc toxicity [1]. Railey et al. suggest that enhanced zinc consumption leads to anxiety and can cause changes in both emotional and spatial learning [2].

In the present study, we want to resolve previous contradictory data by evaluating the effects of zinc supplementation on spatial memory, cognitive function and motor activity in pre- and postnatally exposed rats. Herein, we describe for the first time correlations between the hippocampal content of zinc and spatial memory improvement in supplemented rat pups.

\section{Materials and Methods}

\section{Subjects and Zinc Treatment}

The effect of maternal supplementation with zinc was analysed in the hole board, T-maze, and modified Morris water maze task in 4-week-old male Wistar Charles River rat pups weighing between 100 and 120 g. Pregnant females were housed individually in plastic breeding cages in a temperature-controlled room $\left(22-26^{\circ} \mathrm{C}\right)$, operating on a 12-h light/dark cycle. The dams were checked daily in the morning for pups. After birth, male offsprings were left with dams until 28 days of age.

During pregnancy and lactation, mothers of the testing rats were given free access to food (LABOFEED $\mathrm{H}, \mathrm{Zn}$ $210 \mathrm{mg} / \mathrm{kg}$ ) and tap water (Con, $n=10$ ) or solution of $\mathrm{ZnSO}_{4}$ at doses of $16 \mathrm{mg} / \mathrm{kg}(\mathrm{Zn} 16, n=8)$ and $32 \mathrm{mg} / \mathrm{kg}(\mathrm{Zn} 32$, $n=8$ ) [14]. Zinc solutions were administered perorally in drinking water, and concentrations were adjusted to an average daily intake of 16 and $32 \mathrm{mg} / \mathrm{kg}$ per rat. Zinc administration was continued during behavioural experiments (Fig. 1). Metal-supplemented drinking water was prepared using tap water $(<0.001 \mathrm{mg} \mathrm{Zn} / \mathrm{L})$. Water was analysed regularly to confirm metal content [14].

All experimental procedures involving the use of animals were carried out according to the Ethical Committee for

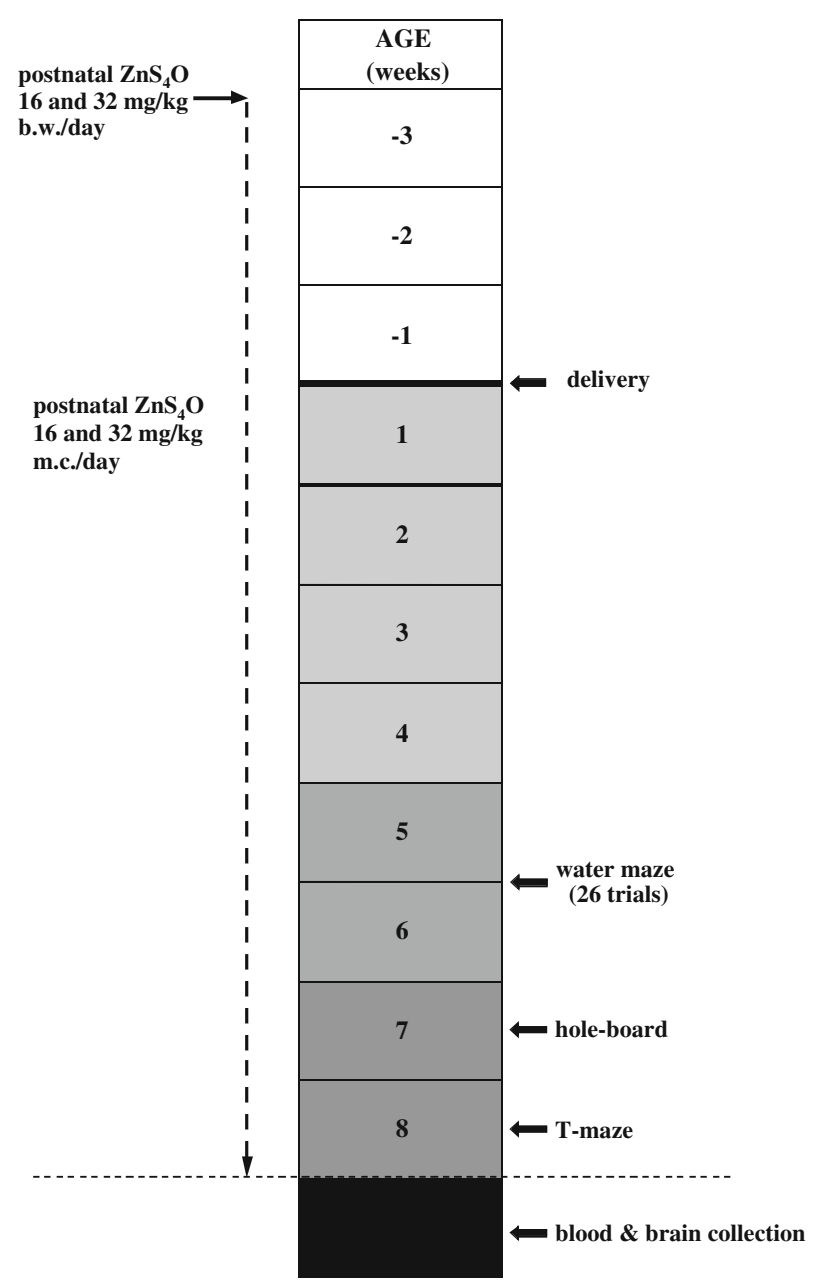

Fig. 1 Scheme of maternal pre- and postnatal zinc treatment and sequence of behavioural tests (Con, $n=10 ; \mathrm{Zn} 16, n=8 ; \mathrm{Zn} 32, n=8$ ) 
Animal Experiments at the Medical University of Warsaw, which are in compliance with the ethical standards of the European Communities Council Directive of 24 November 1986 (86/609/EEC).

\section{Behavioural Tests}

\section{Water Maze Test}

Behavioural observations for spatial learning and memory were made in the water maze, modified from the standard version of the Morris test [15]. The experiment was performed during the light phase of the cycle (between 800 and 1500 hours).

In the task, the animals were trained to find a hidden platform in a swimming pool. A circular white pool $(140 \mathrm{~cm}$ in diameter and $50 \mathrm{~cm}$ deep) was filled to a height of $30 \mathrm{~cm}$ above the base with $23^{\circ} \mathrm{C}$ water. The pool was located in the testing room which contained many objects that could be used by the rats for spatial orientation. The position of the cues was not changed throughout the period of testing. The pool was divided into four quadrants which were arbitrarily designed northeast (NE), northwest (NW), southeast (SE) and southwest $(\mathrm{SW})$. A plexiglass platform $(10 \times 10 \mathrm{~cm})$ was hidden $1 \mathrm{~cm}$ below the water surface. The platform was located in the centre of the SE (acquisition, remainder) or NW (reversal) quadrant.

Each trial was started by placing a rat with its face toward the wall of the pool at one of three start points. The sequence of the starting positions was randomly selected and changed each day. The trial was terminated when the animal entered the platform. If the rat did not find the platform within $60 \mathrm{~s}$, it was placed on the platform by the experimenter for $60 \mathrm{~s}$.

During acquisition (days 1-4, trials 1-16), remainder (day 8, trials 18-21) and reversal (day 9, trials 22-25) of the spatial navigation task, all groups were given one session of four trials each day. At the end of the day's session, the rat was removed from the pool, dried and returned to its home cage. In the probe trial, on the fifth (trial 17) and tenth (trial 26) day of testing, the platform was removed from the pool. The animal was allowed to swim for $60 \mathrm{~s}$ before the end of the session.

Data from Morris's water maze task were automatically recorded using an HVS image analysing system (Chromotrack, San Diego Instruments) and videotaping. Data from the water maze included escape latency and swim speed. For the probe trial, the number of visits to the area in which the platform had been located and percentage of time spent in each quadrant were measured.

\section{Hole Board Test}

The hole board apparatus allowed to measure exploratory and motor activity [16]. It was a wooden square box $(1 \times 1-\mathrm{m}$ floor and height of walls, $0.3 \mathrm{~m}$ ) with an open top for the observer. The hole board apparatus contained 16 square sections $(0.25 \times 0.25 \mathrm{~m})$ with a hole $(3.8 \mathrm{~cm}$ in diameter and $5 \mathrm{~cm}$ deep) located in the middle of each square. The experiment was performed during five consecutive days, each day one session.

To begin the experiment, a rat was placed in the centre of the box, facing away from the observer. An animal was allowed to move freely about the box for $5 \mathrm{~min}$ (one session). The box was cleaned after each session with $10 \%$ solution of vinegar.

During the climbing session, head dips, rearing responses, squares crossed and motor activity were recorded. Head dips were defined as the submergence of the rat's head into one of the holes to eye level. Rearing responses were defined as the rising up on its hind legs with forepaws off the ground. Squares crossed were defined as the number of sections entered, and motor activity was defined as the time spent in movement.

\section{T-maze Test}

T-maze apparatus allowed to measure spontaneous alternation and motor activity. These parameters were measured twice daily during the last week of the $\mathrm{ZnSO}_{4}$ administration. The testing apparatus was a wooden $\mathrm{T}$-maze with an entrance arm $(0.65 \times 0.18 \mathrm{~m})$ and two cross arms $(0.65 \times$ $0.18 \mathrm{~m}$ ); the walls were $0.2 \mathrm{~m}$ high. The alternation session consisted of two trials. In the first trial, a rat was placed at the distal end of the entrance arm, and a choice of left or right and time elapsed were recorded. The criterion for selection of a choice arm was an entrance of the animal's four paws into the cross arm. After entering one of the arms, the rat was removed to a holding cage. After a 60 -s interval, the rat was returned to the start area for a second identical trial. Each day, two sessions were conducted with a $4 \mathrm{~h}$ interval between them. A trial terminated when the animal departed the chosen arm or if no choice was made after $180 \mathrm{~s}$. Between trials, the maze was cleaned with vinegar solution.

Spontaneous alternation is a phenomenon in which an animal's choice of arm on the second trial is opposite from that of the first trial. An alternation percentage was calculated for each animal by way of the following formula: number of correct choices divided by number of sessions and multiplied by 100 .

\section{Biochemistry}

\section{Concentration of Zinc in the Blood}

Rats offsprings were decapitated $24 \mathrm{~h}$ after the last behavioural experiment. The blood was collected in glassy tubes 
and stored in $4^{\circ} \mathrm{C}$ temp. After $24 \mathrm{~h}$, serum was collected and centrifuged at $3,000 \times g$ for $15 \mathrm{~min}$ at $4{ }^{\circ} \mathrm{C}$. The supernatant was transferred to a clean polypropylene tube and frozen at $-80^{\circ} \mathrm{C}$ for long-term storage until an assay for zinc concentrations was done.

The level of zinc in the serum samples was determined with an atomic absorption spectrophotometer (Solar, Pey Unicam) as described by Kalinowski et al. [17]. The level of serum zinc was expressed in micrograms per millilitre.

\section{Zinc Concentration in the Brain}

After decapitation, brains were freshly dissected into two regions - prefrontal cortex and hippocampus-weighed, quickly frozen and then stored in a deep freezer $\left(-80^{\circ} \mathrm{C}\right)$ for future analysis. Next, $2 \mathrm{ml}$ of concentrated nitric acid (d $1.40 \mathrm{~g} / \mathrm{ml}$, JT Baker Analyzed) was added. The tissue samples were microwave digested (Plazmatronika, model SM1) and diluted in $10 \%$ nitric acid. Determination of zinc was performed by atomic absorption spectrometry (Aanalyst 300, Perkin Elmer, USA) as described by Kalinowski et al. [17]. Linear calibration was made with 40, 100 and $500 \mu \mathrm{g} / \mathrm{l}$ of zinc standards prepared from Spectrascan element standard $(1,000 \pm 5 \mu \mathrm{g} / \mathrm{ml}$ in $2.5 \%$ nitric acid $)$ for atomic spectroscopy, with a zinc concentration of $10 \mu \mathrm{g} / \mathrm{ml}$ (Teknolab AB, Drøbak, Norway).

The accuracy of zinc determination was checked using a Quality Control Standard 3 (Cerillant Co., Austin, USA), Bovine Liver reference sample (SRM1577b/Bovine Liver/ NIST, Gaithersburg, USA) and as a blank $0.1 \mathrm{M} \mathrm{HNO}_{3}$ (Suprapur). Reference samples and blanks were run parallel to the samples. The level of zinc in the brain structures was expressed in micrograms per gram of wet tissue.

\section{Statistical Analysis}

Group differences were assessed during analysis of variance (ANOVA) with repeated measures. Significant effects were further analysed by post hoc analyses (Newman-Keuls test and Student's $t$ test) to determine specific differences. The correlation between behavioural parameter (crossing in SE during the fifth day) and level of zinc in the hippocampus and prefrontal cortex was determined using Pearson's product moment correlation.

\section{Results}

Water Maze Results

\section{Acquisition Trials (Days 1-4)}

The latency to find the hidden platform for all experimental groups is presented in Fig. 2. A repeated measures ANOVA revealed significant differences between groups in the acquisition of water maze $\left(F_{(2,23)}=24.5, p<0.001\right)$. A significant treatment $\times$ day interaction: $F_{(6,69)}=2.88, p<0.05$ and for treatment $\times$ trials: $F_{(18,207)}=3.64, p<0.01$ was found. The mean escape latency over 4 days for the control group $(44.8 \pm 1.6 \mathrm{~s})$ and $\mathrm{Zn} 32(34.1 \pm 2.4 \mathrm{~s})$ was significantly greater that the $\mathrm{Zn} 16$ group $(26.2 \pm 1.6 \mathrm{~s})$ (Newman-Keuls test, $p<0.01)$.

\section{The Probe Trial (Day 5)}

In the probe trial on day 5, statistical analysis of annulus crossings above the original platform position showed a significant improvement in both $\mathrm{ZnSO}_{4}$ supplemented groups with the ANOVA main effect $F_{(2,23)}=9.3, p<0.01$. Post hoc analysis revealed that supplementation of $\mathrm{ZnSO}_{4}$ in doses of 16 and $32 \mathrm{mg} / \mathrm{kg}$ per rat (Zn16, 5.75 $\pm 0.9 ; \mathrm{Zn} 32$, $4.4 \pm 0.2)$ increased annulus crossings relative to the performance of the control (Con, $2.3 \pm 0.5$ ) (Newman-Keuls test, $p<0.05$ ) (Fig. 3).

There was a significant difference between the groups in the percentage of time spent in the SE quadrant (quadrant in which the platform had been situated earlier): $F_{(2,23)}=15.3, p<0.01$; NW quadrant (mirror reflection of the SE quadrant): $F_{(2,23)}=$ 10.14, $p<0.01$; and the NE quadrant (starting position):
Fig. 2 Escape latency ( \pm S.E. $)$ during acquisition of the spatial navigation task (16 trials) for the control $(n=10)$ and rats pre- and postnatally supplemented with $\mathrm{ZnSO}_{4}(\mathrm{Zn} 16$, $n=8 ; \mathrm{Zn} 32, n=8$ )

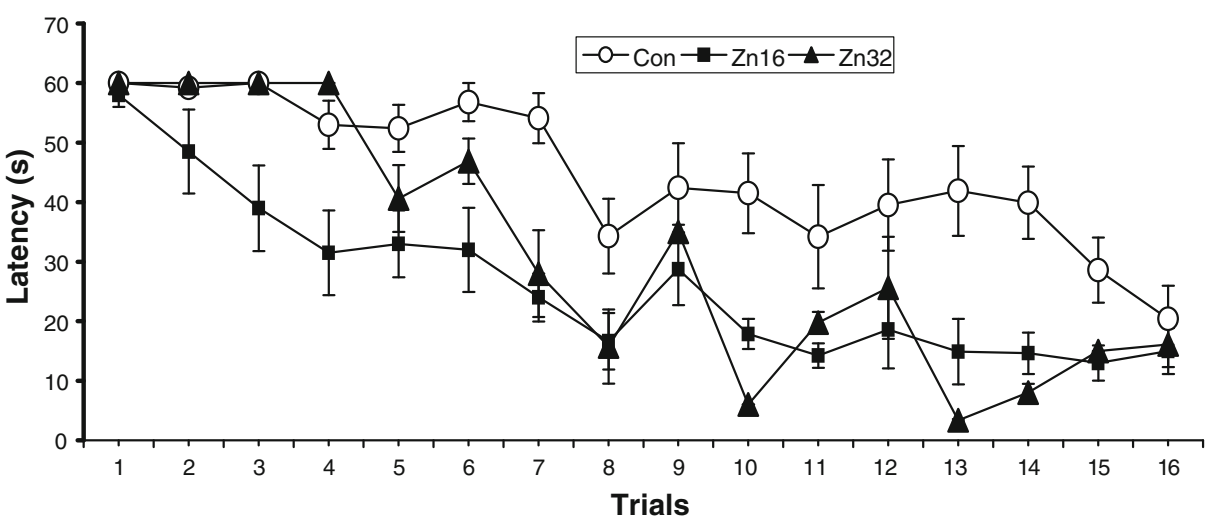




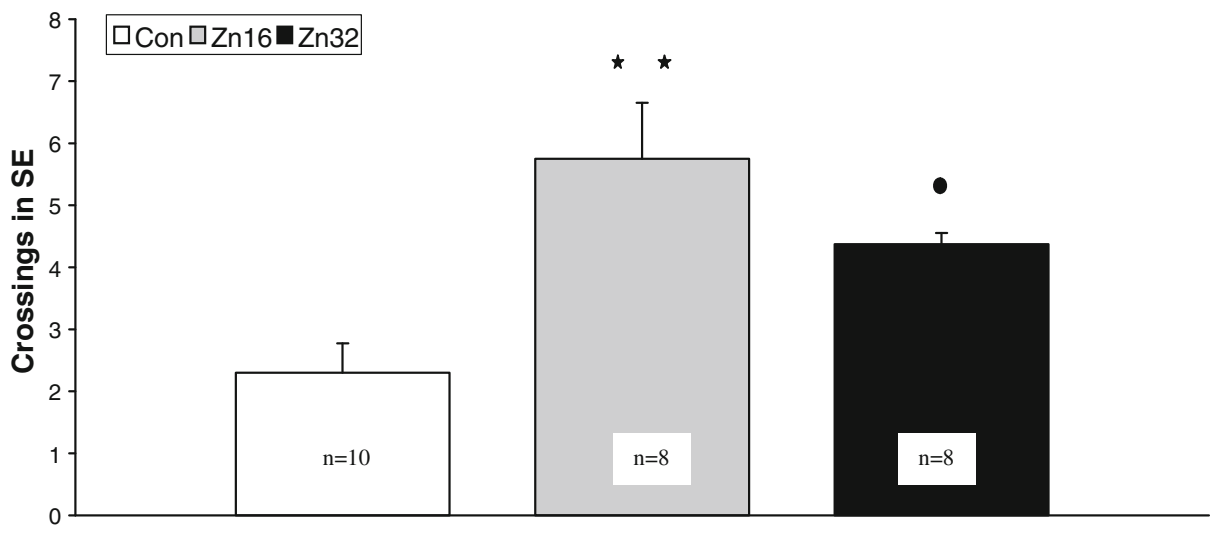

Fig. 3 Spatial probe data from the platform area crossings for the control and $\mathrm{ZnSO}_{4}$-treated rats in the water maze task on day 5 (trial 17). The test was run in the same manner as the acquisition trials, except that the target was absent and the trial was terminated after $60 \mathrm{~s}$.
The measure given is platform crossings \pm S.E.: the number of times the rat passed through a nominal area defining the originally correct platform position. ${ }^{* *} p<0.01, \mathrm{Zn} 16$ vs control; $\bullet p<0.05, \mathrm{Zn} 32$ vs control (Newman-Keuls test)
$F_{(2,23)}=4.7, p<0.05$. The time spent in the target quadrant (SE) was significantly longer for the zinc-treated group: Zn16 (28.43 \pm 1.71$), \operatorname{Zn} 32(26.5 \pm 0.18)$ compared to the control $(17.75 \pm 1.77)$ (Newman-Keuls test, $p<0.01)$ (Fig. 4).

\section{Remainder Trials (Day 8)}

After 2 days' break, the training on the regular four trials was reinstated with platform position still in SE. ANOVA showed that the groups differed $\left(F_{(2,23)}=7.1, p<0.01\right)$. Latencies were significantly reduced as a function of trials $\left(F_{(3,69)}=6.8, p<0.001\right)$. A significant treatment $\times$ trial interaction was found $\left(F_{(6,69)}=3.7, p<0.01\right)$. The control group $(30.05 \pm 3.02 \mathrm{~s})$ had a significantly longer mean escape latency that Zn16 (10.8 $\pm 1.4 \mathrm{~s} ; p<0.01$, Newman-Keuls test) and Zn32 (19.5 $\pm 3.3 \mathrm{~s} ; p<0.05, t$ test $)$. There was not a significant effect for speed.

\section{Transfer Test (Day 9)}

In day 9 , the platform position was reversed to the opposite quadrant (NW) that was used for initial training. To permit direct comparisons of crossings over the old goal (SE), the observed crossing for each group was normalised by the ratio of the relative corrected crossing (the crossings of trial 22 divided by the escape latency and multiplied by 60 ). ANOVA on the transformed scores did not show any significant effects for zinc supplementation $\left(F_{(2,23)}=2.2, p>\right.$ $0.05)$, but latencies were significantly reduced as a function of trials $\left(F_{(3,69)}=13.8, p<0.001\right)$, and interaction group $\times$
Fig. 4 The percentage of time spent in quadrants for the control $(n=10)$ and $\mathrm{ZnSO}_{4}$ (Zn16, $n=8 ; \mathrm{Zn} 32, n=8)$ treated rats in the water maze task on day 5 (trial 17). The test was run in the same manner as the acquisition trials, except that the target was absent and the trial was terminated after 60 s. ${ }^{* *} p<0.001, \mathrm{Zn} 16$ and Zn32 vs control; $* p<0.05$, Zn16 vs control; $\bullet p<0.01$, Zn16 vs Zn32 (NewmanKeuls test)

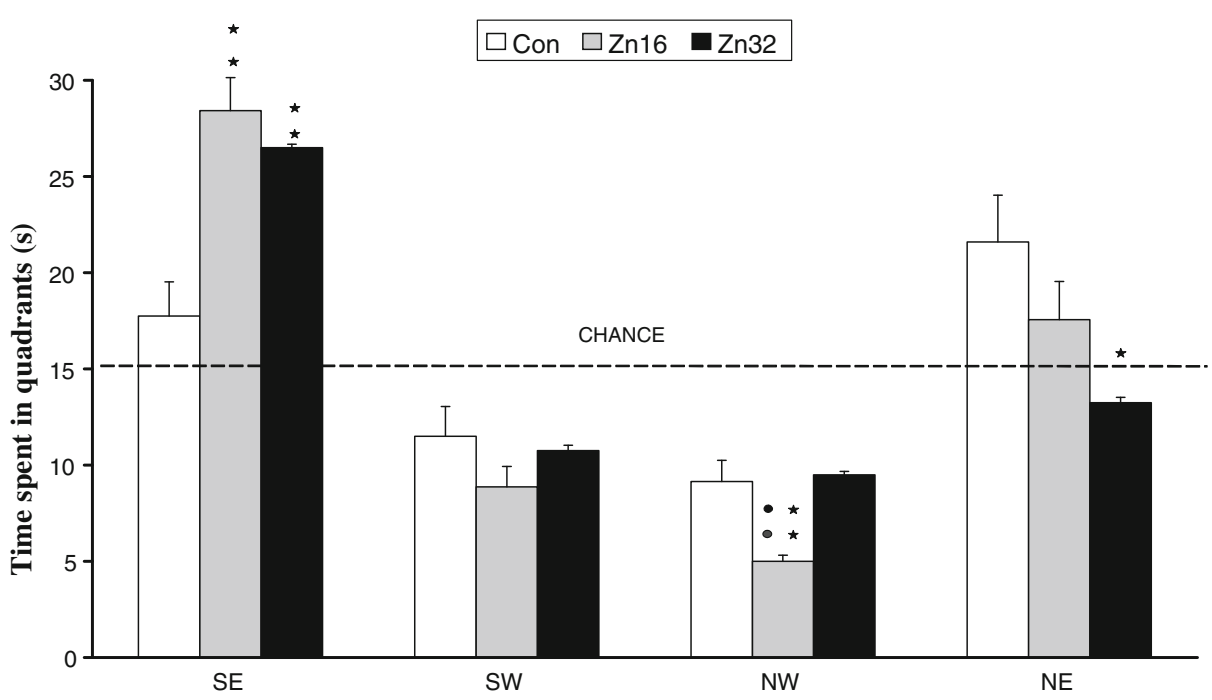


trials was significant $\left(F_{(6,69)}=4.9,0<0.01\right)$. The $\mathrm{Zn} 16$ group showed the shortest mean escape latency $(25.3 \pm 3.3 \mathrm{~s}) \mathrm{com}-$

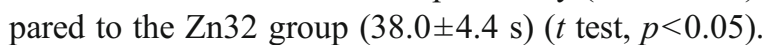

\section{The Probe Trial (Day 10)}

During the probe trial on day 10 , both control and treated rats did not show a significant difference in the number of annulus crossings both in the old platform position (SE): $F_{(2,23)}=2.03, p>0.05$ and in the new location (NW): $F_{(2,23)}=$ $1.7, p>0.05$. However, the Zn16 group spent significantly longer time (21.5 $\pm 1.6 \mathrm{~s})$ in the SE quadrant compared to the control (16.6 \pm 1.9$)$ and the $\mathrm{Zn} 32$ group (16.5 $\pm 0.2 \mathrm{~s})(t$ test, $p<0.05)$. Then, the $\mathrm{Zn} 32$ group spent a significantly shorter time $(9.5 \pm 0.2 \mathrm{~s})$ in the NW quadrant compared to the control $(13.3 \pm 1.5 \mathrm{~s})(t$ test, $p<0.05)$.

\section{Hole Board Results}

The effect of treatment was significant in the mean number of climbings among examined groups $\left(F_{(2,23)}=10.04, p<0.001\right)$ and days of training $\left(F_{(4,92)}=4.03, p<0.01\right)$. The NewmanKeuls multiple comparison test revealed an increase in climbing of the $\mathrm{Zn} 16$ group ( $3.8 \pm 0.3$ ) in comparison to the control group $(1.7 \pm 0.2)$ and the $\mathrm{Zn} 32$ group $(2.1 \pm 0.2)(p<0.01)$ (Fig. 5). There was not a significant effect in the analysis of the number of head dips $\left(F_{(2,23)}=0.4, p>0.05\right)$, crossings $\left(F_{(2,23)}=0.4, p>0.05\right)$ and motor activity $\left(F_{(2,23)}=0.4, p>0.05\right)$.

\section{T-maze Results}

The analysis of the alternation percentage showed a significant difference $\left(F_{(2,23)}=5.04, p<0.05\right)$ (Fig. 6). Treatment with zinc at $16 \mathrm{mg} / \mathrm{kg} /$ day was found to change significantly the spontaneous alternation behaviour compared to the control and Zn32 group ( $p<0.05$, Newman-Keuls test). Latency to choose a goal arm was not altered by zinc treatment $\left(F_{(2,23)}=1.3, p>0.05\right)$.

\section{Serum Zinc Level}

ANOVA demonstrated significant differences in the content of zinc in the serum from rat pups treated with zinc compared to the control $\left(F_{(2,23)}=8.4, p<0.01\right)$. A higher concentration of zinc was observed in groups Zn16 and Zn32 ( $p<0.05$, Newman-Keuls test) (Table 1).

\section{Hippocampal and Cortical Zinc Level}

The levels of zinc in the prefrontal cortex and hippocampus are summarised in Table 2. ANOVA demonstrated a significant increase in the cortical $\left(F_{(2,23)}=5.14, p<0.02\right)$ and hippocampal $\left(F_{(2,23)}=4.12, p<0.05\right)$ zinc concentrations in the brains of rats pre- and postnatally treated with $\mathrm{ZnSO}_{4}$ compared to the control $(p<0.05$, Newman-Keuls test) (Table 2).

\section{Zinc Levels and Spatial Memory Correlation}

The number of crossings over the previous position of the platform during the probe trial (day 5) was compared with the levels of zinc in the prefrontal cortex and hippocampus. It has been shown that zinc concentration in the hippocampus of the $\mathrm{Zn} 16$ and $\mathrm{Zn} 32$ groups correlated positively with results of the probe trial $\left(\mathrm{Zn} 16: r=0.765, p<0.05, F_{(1,6)}=\right.$ 8.46, intercept $=-29.62 ; \mathrm{Zn} 32: r=0.7224, p<0.05, F_{(1,6)}=$
Fig. 5 Mean number of climbings ( \pm S.E.) during hole board for the control and rats pre- and postnatally supplemented with $\mathrm{ZnSO}_{4}{ }^{* *} p<0.01$, Zn16 vs control; $\bullet p<0.01$, Zn32 vs Zn16 (NewmanKeuls test)

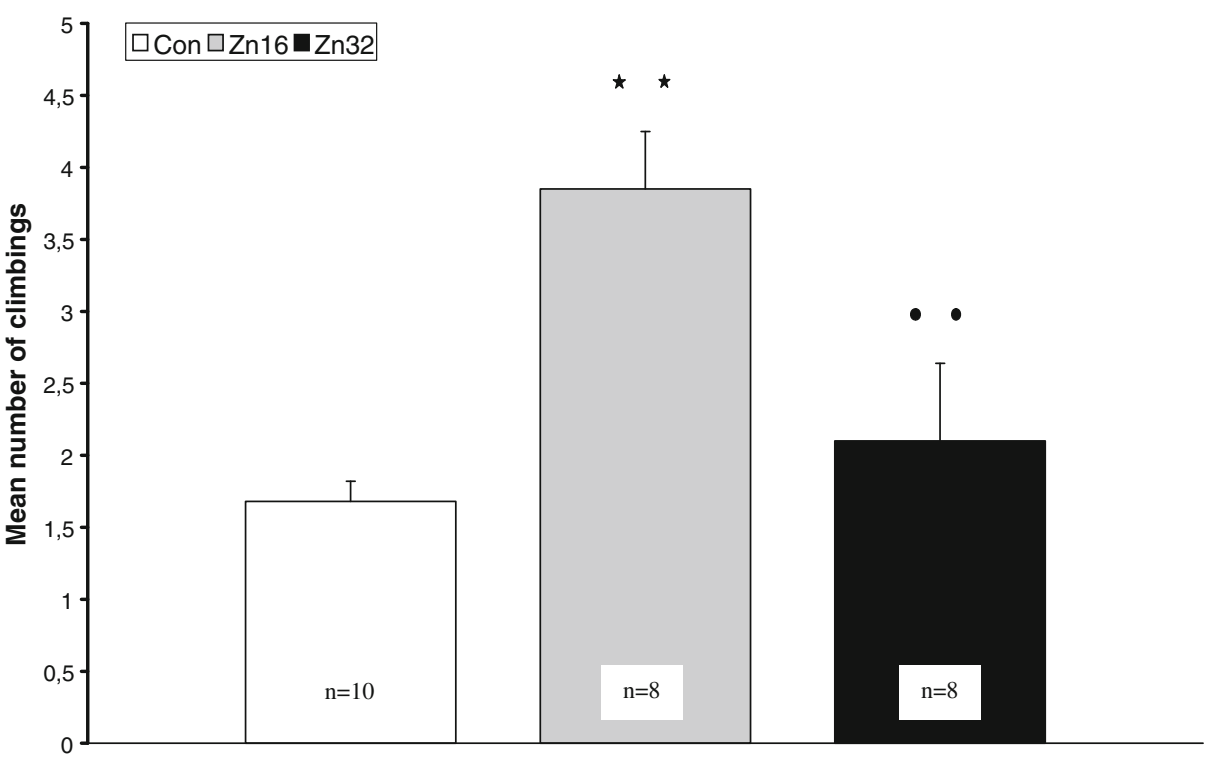


Fig. 6 T-maze spontaneous alternation $( \pm$ S.E.) average of all trials. $* p<0.05, \mathrm{Zn} 16$ vs control; $\bullet p<0.01, \mathrm{Zn} 32$ vs Zn16 (Newman-Keuls test)

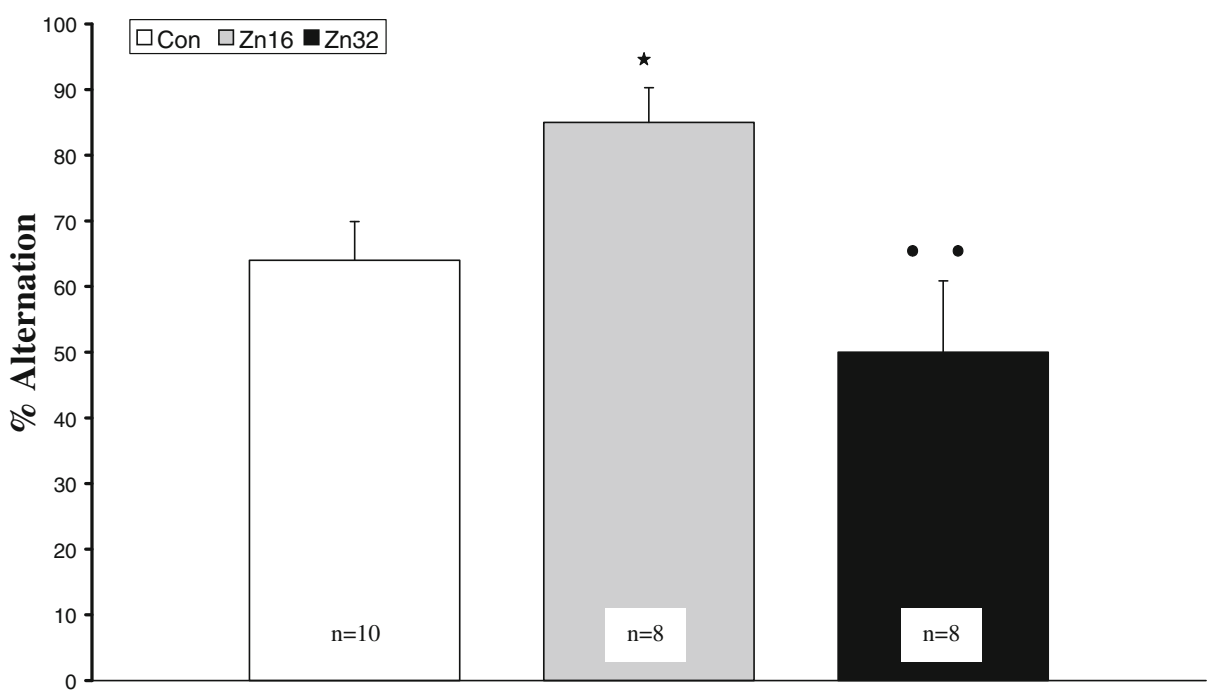

6.55 , intercept $=-6.08$ ). The accuracy of spatial memory was not reliably correlated with hippocampal zinc level in the control rats (Con: $r=0.569, p>0.05, F_{(1,8)}=3.83$, intercept $=13.88$ ). The accuracy of spatial memory was not reliably correlated with zinc concentration in the prefrontal cortex in all tested groups.

\section{Discussion}

Zinc can exert a modulatory effect through the inhibition or potentiation of receptors and ion channels and influence variety transporters and second messengers systems. This transitional metal stabilizes hundreds of enzymes and other proteins. Proper zinc level is required for normal cognitive abilities and is important for the control, functioning and development of the brain. Maternal zinc deficiency disturbs prenatal and postnatal brain maturation, e.g. suppresses the development of neural stem cells, may lead to brain malformation, changes in the cerebellum and hippocampus and other neuroanatomical and behavioural abnormalities [18]. Zinc restriction during pregnancy has shown behavioural manifestation in offsprings, elicits neuropsychological symptoms, e.g. apathy and aggression, and affects cognitive performance [19].

Table 1 Effect of pre- and postnatal zinc supplementation on serum zinc levels in rat pups

\begin{tabular}{lc}
\hline Group & Serum zinc level $(\mu \mathrm{g} / \mathrm{ml})$ \\
\hline Con $(n=10)$ & $1.10 \pm 0.03$ \\
Zn16 $(n=8)$ & $1.24 \pm 0.03^{*}$ \\
Zn32 $(n=8)$ & $1.35 \pm 0.06^{* *}$ \\
\hline
\end{tabular}

Data are presented as mean \pm S.E. levels (micrograms per millilitre) ${ }^{*} p<0.05, \mathrm{Zn} 16$ vs control; ${ }^{* *} p<0.005, \mathrm{Zn} 32$ vs control
The present study demonstrates significant improvement of spatial learning and memory processes after zinc supplementation during ontogenesis in rat pups. In the water maze memory test on day 5 , the analysis of annulus crossings above the original platform position showed a significant amelioration in both $\mathrm{ZnSO}_{4}$-supplemented groups.

Our current findings are consistent with reports of cognitive impairment caused by nutritional zinc deficiency. Tahmasebi Boroujeni et al. have analysed the effects of the diet deficient in zinc $(0.5-1.5 \mathrm{ppm})$ and zinc-enhanced diet $(10 \mathrm{ppm})$ on spatial learning, memory and motor activity in the water maze and open field in rats [20]. These authors reached important conclusions: first, that zinc deficiency during the last trimester of pregnancy and during lactation impaired spatial learning and memory in offsprings, and second, that zinc deprivation decreased neuromotor performance. Similarly, zinc deficiency impaired spatial memory in elevated T-maze and 17-arm radial maze but had no effect on reference memory [21].

Watanabe et al. suggest that zinc deprivation in young rats elicits abnormal behaviour in stressful conditions [22]. Similar conclusions were reached by $\mathrm{Chu}$ et al. for zinc-

Table 2 Effect of pre- and postnatal zinc supplementation on brain tissue zinc levels in rat pups

\begin{tabular}{lcc}
\hline Group & \multicolumn{2}{l}{ Zinc level in the brain, $\mu \mathrm{g} / \mathrm{g}$ wet tissue } \\
\cline { 2 - 3 } & Prefrontal cortex & Hippocampus \\
\hline Con $(n=10)$ & $14.08 \pm 0.25$ & $14.47 \pm 0.21$ \\
Zn16 $(n=8)$ & $15.11 \pm 0.24^{*}$ & $15.31 \pm 0.29^{*}$ \\
Zn32 $(n=8)$ & $15.28 \pm 0.38^{* *}$ & $15.22 \pm 0.19^{* *}$ \\
\hline
\end{tabular}

Data are presented as mean \pm S.E. levels (micrograms per gram wet tissue)

${ }^{*} p<0.05, \mathrm{Zn} 16$ vs control; ${ }^{* *} p<0.05, \mathrm{Zn} 32$ vs control 
deprived and pair-fed rats [23]. The water maze results indicate a possible role of stress status and elevated corticosterone in observed deterioration of the short-term memory and anxiety-like behaviour in zinc-restricted rats [23]. Accordingly, depression-like behaviour in zinc deficiency observed during forced swimming test is linked to the abnormal increase in extracellular glutamate and elevated serum corticosterone concentration in animals [22].

There are also some conflicting data regarding the zinc supplementation on learning, memory and motor activity. Excess dietary zinc leads to copper deficiency which can produce impairments in cognition. Chronic postnatal intoxication with zinc did not interfere with the exploratory behaviour and did not alter memory retention in an inhibitory avoidance model in mice [24]. Moreover, rats supplemented pre- and postnatally with zinc carbonate demonstrated a lack of extinction to the tone in cued fear conditioning [25]. Previous animal studies have shown that enhanced levels of zinc in drinking water lead to deficits in spatial learning in 3-and 9-month-old rats and an increase of zinc levels in the brain. In contradiction with our results, Turner and Soliman have reported that systemic supplementation of adult rats in zinc chloride (50 or $100 \mathrm{ng} / \mathrm{kg}$ ) leads to behavioural deficits observed in the water maze test [26]. Also, Flinn et al. have found spatial memory deficits in rats consuming elevated dietary zinc [27]. Keller et al. emphasize an age-dependent influence of dietary zinc restriction on short-term memory and indicate that only rats younger than 62 days of age are sensitive to zinc deficits [28].

Even though some researchers have not agreed that dietary zinc consumption translates to changes in the levels of zinc within the brain due to regulation by the blood-brain barrier, follow-up data revealed significant elevated zinc levels in the serum, hippocampus and prefrontal cortex in pre- and postnatally zinc-supplemented rats [2, 29].

Zinc is found throughout the whole body with relatively high concentrations within the central nervous system. Zinc homeostasis in the brain is tightly regulated by the brain barrier system; however, the poll of zinc can be reduced by zinc deficiency and results in abnormal glucocorticoid secretion. Vesicular zinc is found within glutamatergic, glycinergic and GABA-ergic neurons. These zincergic neurons are found within the hippocampus, cortex, olfactory bulb and amygdala [11]. The development of the hippocampus and cortex is accompanied by characteristic changes in the distribution and levels of vesicular zinc. Levels of zinc in the hippocampal area are greater than those of any other element, including calcium and iron. It was reported that zinc levels in the hippocampus, particularly in the mossy fibres (MFs), increase during the early neonatal period in rats. The hippocampal mossy fibre pathway is involved in the modulation of processes related to spatial learning and memory [30]. Strong stimulation of the hippocampal MFs augmented the release of the endogenous zinc from these fibres. The extracellular concentration of the discharged zinc may reach $300 \mu \mathrm{M}$ at the peak of convulsive activity. We have shown that an increased zinc level in the hippocampus correlated positively with the memory of the position of the platform in the probe trial during the water maze test.

It may be reasonable to speculate that alteration of zinc homeostasis in the hippocampus and cerebral cortex is involved in the transient learning impairment in zinc-deficient adult rats [31-33]. Other evidence supports the assumption that dietary deficiency of this important divalent cation affects its hippocampal homeostasis resulting in the failure in passive avoidance [31].

Moreover, the real-time RT-PCR during spatial learning of rats in the water maze provides data concerning zinc homeostasis-related gene expression in the hippocampus. Forced physical exercise improves cognitive ability and mobilizes mRNA expression of zinc transporters (ZnT-2, ZnT-4, ZnT-5, ZnT-6, ZnT-7), metallothioneins, divalent cation transporter-1 and Zrt-Irt like proteins-7 [34].

Additionally, impaired hippocampal learning and memory under zinc deficiency is associated with the disruption of the signalling molecules essential for long-term potentiation, e.g. calmodulin ( $\mathrm{CaM})$ and phosphorylated CaMdependent protein kinase II [35]. Mafra and Cozzolino have shown the relationship between the elevated erythrocyte zinc concentration and carbonic anhydrase levels - zinc-containing enzyme involved in the synaptic plasticity, learning and memory processes [36].

It has been demonstrated that the low dose of $\mathrm{ZnSO}_{4}$ is more effective than the higher one. In our study, latency to choose a goal arm in T-maze was not significantly altered by zinc treatment; however, a lower dose of zinc was found to change significantly spontaneous alternation behaviour. In addition, maternal supplementation with $16 \mathrm{mg}$ of zinc significantly increased the climbing and the pattern of general exploratory activity in the hole board. Other evidence supports the dose-dependent effect of zinc supplementation on short-term memory in young rats in a shuttle box [37]. It is also apparent that chelation of zinc in vitro leads to the inhibition of LTP; however, high concentrations of zinc $(300 \mu \mathrm{M})$ can inhibit LTP and CA1 and CA3 synapses [38]. All these observations are in full agreement with hormesis conception.

These data are in agreement with previous reports indicating that zinc is able to biphasically modulate nicotinic, serotonergic, glutamate, NMDA and GABA receptors. Further, zinc has been shown to protect neurons from neurodegeneration and excitotoxic insult induced by NMDA or glutamate [39, 40]. Increased zinc levels within the brain could act in terms of the GABA antagonist and can lead to the reduction in NMDA receptor expression and activity [7]. 
Additionally, the neuromodulatory effect of zinc may be connected with its antioxidant properties. This micronutrient compound can exert a lot of antioxidant functions as protection against vitamin $\mathrm{E}$ depletion, stabilization of the membrane structure and restriction of endogenous free radical production. It was also shown that the administration of antioxidant compounds or inhibition of free radical oxidation in early postnatal ontogenesis and infancy leads to facilitation of the learning process and improvement of cognitive development [39].

In conclusion, our studies provided direct evidence of the dose-dependent improvement of spatial learning and memory in rat pups after pre- and postnatal zinc administration. The data obtained in this investigation deliver further proof of hippocampal involvement in the cognitive benefits observed after early zinc supplementation.

Acknowledgements The authors declare that they have no competing interests. This research received no specific grant from any funding agency in the public, commercial or not-for-profit sectors.

Open Access This article is distributed under the terms of the Creative Commons Attribution Noncommercial License which permits any noncommercial use, distribution, and reproduction in any medium, provided the original author(s) and source are credited.

\section{References}

1. Halas ES, Wallwork JC, Sandstead HH (1982) Mild zinc deficiency and undernutrition during the prenatal and postnatal periods in rats: effects on weight, food consumption, and brain catecholamine concentrations. J Nutr 112:542-551

2. Railey AM, Micheli TL, Wanschura PB, Flinn JM (2010) Alterations in fear response and spatial memory in pre- and post-natal zinc supplemented rats: remediation by copper. Physiol Behav 100:95-100

3. Shahbazi M, Naghdi N, Tahmasebi S, Sheikh M, Namvar AN, Kazemnejad A (2009) The effect of iron and zinc dietary restriction of pregnant rats on physical growth of litters. Biol Trace Elem Res 128:232-238

4. Vallee BL, Falchuk KH (1993) The biochemical basis of zinc physiology. Physiol Rev 73:79-118

5. Tomat A, Elesgaray R, Zago V, Fasoli H, Fellet A, Balaszczuk AM, Schreier L, Costa MA, Arranz C (2010) Exposure to zinc deficiency in fetal and postnatal life determines nitric oxide system activity and arterial blood pressure levels in adult rats. Br J Nutr 104:382-389

6. Tomat AL, Costa ML, Arranz CT (2011) Zinc restriction during different periods of life: influence in renal and cardiovascular diseases. Nutrition 27:392-398

7. Chowanadisai W, Kelleher SL, Lönnerdal B (2005) Maternal zinc deficiency reduces NMDA receptor expression in neonatal rat brain, which persists into early adulthood. J Neurochem 94:510-519

8. Halas ES, Eberhardt MJ, Diers MA, Sandstead HH (1983) Learning and memory impairment in adult rats due to severe zinc deficiency during lactation. Physiol Behav 30:371-381

9. Brown LY, Kottmann AH, Brown S (2003) Immunolocalization of Zic2 expression in the developing mouse forebrain. Gene Expr Patterns 3:361-367
10. Corniola RS, Tassabehji NM, Hare J, Sharma G, Levenson CW (2008) Zinc deficiency impairs neuronal precursor cell proliferation and induces apoptosis via p53-mediated mechanisms. Brain Res 1237:52-61

11. Nakashima AS, Dyck RH (2009) Zinc and cortical plasticity. Brain Res Rev 59:347-373

12. Smart TG, Xie X, Krishek BJ (1994) Modulation of inhibitory and excitatory amino acid receptor ion channels by zinc. Prog Neurobiol 42:393-441

13. Ono S, Cherian MG (1999) Regional distribution of metalothionein, zinc, and copper in the brain of different strains of rats. Biol Trace Elem Res 69:151-159

14. Maret W, Sandstead HH (2006) Zinc requirements and the risks and benefits of zinc supplementation. J Trace Elem Med Biol 20:3-18

15. Widy-Tyszkiewicz E, Scheel-Krüger J, Christensen AV (1993) Spatial navigation learning in spontaneously hypertensive, renal hypertensive and normotensive Wistar rats. Behav Brain Res 54:179-185

16. File SE, Wardill AG (1975) The reliability of the hole-board apparatus. Psychopharmacologia 44:47-51

17. Kalinowski M, Wolf G, Markefski M (1983) Concentration and subcellular localization of zinc in the hippocampal formation, cerebellum, and whole brain during the postnatal development of the rat. Acta Histochem 73:33-40

18. Wang F, Zhao F, Guo J, Jing N (2000) Mechanism of impairment to microtubule polymerization resulting from zinc deficiency during pregnancy and lactation in mice. Wei Sheng Yan Jiu 29:156-158

19. Takeda A, Tamano H (2009) Insight into zinc signaling from dietary zinc deficiency. Brain Res Rev 62:33-44

20. Tahmasebi Boroujeni S, Naghdi N, Shahbazi M, Farrokhi A, Bagherzadeh F, Kazemnejad A, Javadian M (2009) The effect of severe zinc deficiency and zinc supplement on spatial learning and memory. Biol Trace Elem Res 130:48-61

21. Devito L, Nassar L (2000) The effects of severe zinc deficiency on the spatial working memory of young and adult female rats. Col Univ J Sci 32:155-162

22. Watanabe M, Tamano H, Kikuchi T, Takeda A (2010) Susceptibility to stress in young rats after 2-week zinc deprivation. Neurochem Int $56: 410-416$

23. Chu Y, Mouat MF, Harris RB, Coffield JA, Grider A (2003) Water maze performance and changes in serum corticosterone levels in zinc-deprived and pair-fed rats. Physiol Behav 78:569-578

24. de Oliveira FS, Viana MR, Antoniolli AR, Marchioro M (2001) Differential effects of lead and zinc on inhibitory avoidance learning in mice. Braz J Med Biol Res 34:117-120

25. Chrosniak LD, Smith LN, Flinn JM, McDonald C, Jones BF (2006) Effects of enhanced zinc and copper in drinking water on spatial memory and fear conditioning. J Geochem Explor 88:91-94

26. Turner TY, Soliman MR (2000) Effects of zinc on spatial reference memory and brain dopamine (D1) receptor binding kinetics in rats. Prog Neuropsychopharmacol Biol Psychiatry 24:1203-1217

27. Flinn JM, Hunter D, Linkous DH, Lanzirotti A, Smith LN, Brightwell J, Jones BF (2005) Enhanced zinc consumption causes memory deficits and increased brain levels of zinc. Physiol Behav 83:793-803

28. Keller KA, Grider A, Coffield JA (2001) Age-dependent influence of dietary zinc restriction on short-term memory in male rats. Physiol Behav 72:339-348

29. Knight J (2000) Metalheads. New Sci 2253:37-39

30. Schwegler H, Crusio WE, Brust I (1990) Hippocampal mossy fibers and radial-maze learning in the mouse: a correlation with spatial working memory but not with non-spatial reference memory. Neurosci 34:293-298

31. Takeda A (2000) Movement of zinc and its functional significance in the brain. Brain Res Brain Res Rev 34:137-148 
32. Takeda A, Takefuta S, Okada S, Oku N (2000) Relationship between brain zinc and transient learning impairment of adult rats fed zinc-deficient diet. Brain Res 859:352-357

33. Takeda A, Tamano H, Tochigi M, Oku N (2005) Zinc homeostasis in the hippocampus of zinc-deficient young adult rats. Neurochem Int 46:221-225

34. Ni H, Li C, Feng X, Cen JN (2011) Effects of forced running exercise on cognitive function and its relation to zinc homeostasisrelated gene expression in rat hippocampus. Biol Trace Elem Res 142:704-712

35. Gao HL, Xu H, Xin N, Zheng W, Chi ZH, Wang ZY (2011) Disruption of the CaMKII/CREB signaling is associated with zinc deficiency-induced learning and memory impairments. Neurotox Res 19:584-591
36. Mafra D, Cozzolino SM (2004) Erythrocyte zinc and carbonic anhydrase levels in nondialysed chronic kidney disease patients. Clin Biochem 37:67-71

37. Moazedi AA, Ghotbeddin Z, Parham GH (2007) Comparison of the effects of dose-dependent zinc chloride on short-term and longterm memory in young male rats. Pak J Biol Sci 10:2704-2708

38. Xie X, Smart TG (1994) Modulation of long-term potentiation in rat hippocampal pyramidal neurons by zinc. Pflugers Arch 427:481-486

39. Choi DW, Koh JY (1998) Zinc and brain injury. Annu Rev Neurosci 21:347-375

40. Côté A, Chiasson M, Peralta MR 3rd, Lafortune K, Pellegrini L, Tóth K (2005) Cell type-specific action of seizure-induced intracellular zinc accumulation in the rat hippocampus. J Physiol 566:821-837 